

\title{
Imagens insurgentes: notas sobre a fotografia urbana no Ceará
}

\author{
Insurgent images: notes on urban photography in Ceará
}

\author{
0smar Gonçalves dos Reis Filho*
}

Resumo: O presente artigo procura investigar uma inflexão estética importante na fotografia cearense: a emergência da cidade como dispositivo, como um tema privilegiado, uma categoria topológica. Dialogando com os trabalhos de Benjamin, Certeau e Rancière, nos interessa propor aqui uma análise que entrelaça as dimensões estética e política da fotografia. Trata-se de pensar o que pode a imagem fotográfica diante das transformações abusivas pelas quais passam hoje cidades como Fortaleza? Como ela poderia intervir no espaço urbano, reconfigurando os territórios sensiveis, apontando para novas formas de viver e habitar juntos? Para tanto, propomos uma interseção teórica e analítica com o ensaio Gente no Centro (2011), de Silas de Paula..

Palavras-chave: Fotografia Urbana. Estética e Politica. Imagens Insurgentes.

Abstract: The present paper intends to investigate an important
aesthetic inflection on the cearense photography: the emergency of
the city as a dispositive, as a privileged theme, a topological category.
Dialoguing with the works of Benjamin, Certeau, Rancière, it interests
us to propose here an analysis that interweave the aesthetics and
political dimensions of photography. It is a question of thinking what
the photographic image can do beyond the abusive transformation
through which cities such as Fortaleza pass today. How could it
intervene on the urban space, reconfiguring the sensitive territories,
pointing to the new forms of living and dwelling together? Therefore,
we propose a theoretical and analytical intersection with the essay
Gente no Centro (2011), by Silas de Paula.
Keywords: Urban Photography. Aesthetics and Politics. Insurgent
Images.

* Universidade Federal do Ceará 
"As ruas têm alma". João do Rio (2008)

"Você sabe melhor do que ninguém, sábio Kublai, que jamais se deve confundir uma cidade com o discurso que a descreve. Contudo, existe uma relação entre eles".

Ítalo Calvino(2004)

\section{Uma nova linha de força}

A fotografia cearense sempre foi marcada por uma forte tradição documental, por um olhar de inspiração jornalística, mais voltado ao registro e à memória de suas festas populares, das manifestações culturais e religiosas locais. Basta ver algumas das obras mais reconhecidas e premiadas do Estado: de Mucuripe, de Chico Albuquerque a Benditos, de Tiago Santana, de Coração Sertão, de Gentil Barreira a Francisco do Canindé, de Chico Gomes.

Trata-se de uma fotografia voltada, de um lado, para o sertão, para "esta imensa campina, que se dilata por horizontes infindos", como nos diz o vaqueiro Arnaldo, no célebre $O$ Sertanejo, de José Alencar (1997, p.7). Uma terra incógnita banhada por um sol titânico que nos é apresentada ora num tom romântico e melancólico, como a morada do "bom selvagem", como um lugar quase aprazível que possibilitaria o reencontro do homem com uma natureza idílica; ora através de um realismo desencantado e corrosivo, à maneira de um Graciliano Ramos (SANTANA; DANTAS, 2007) que preferia mostrar o que há de brutal nessa terra inóspita, um território de morte eminente e de luta constante; sertão das secas e da fome, onde apenas o mais fortes sobrevivem (Figura 1). 
Figura 1 - O Chão de Graciliano (2007)

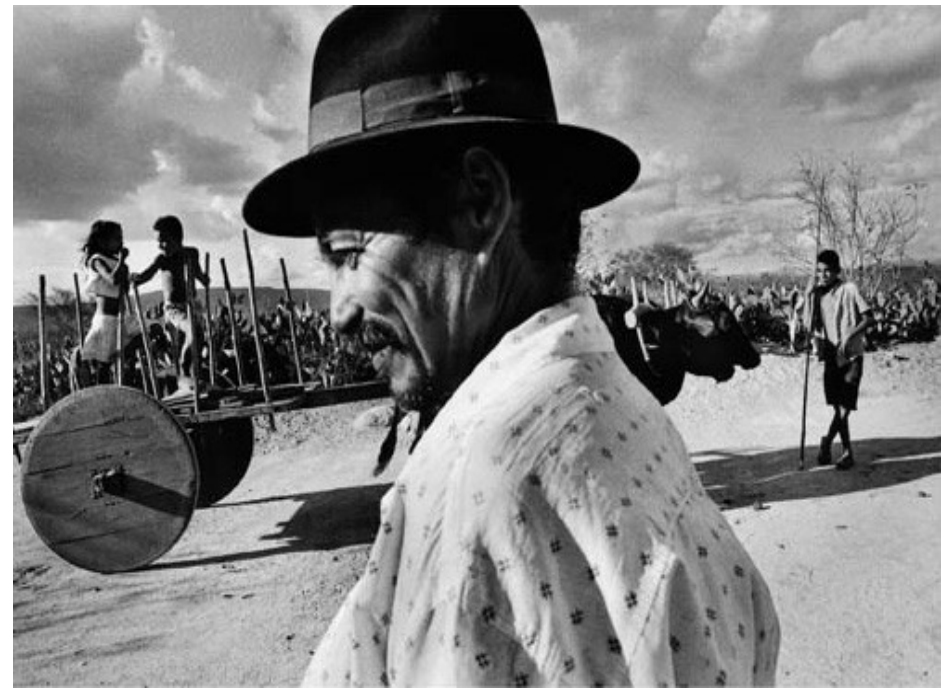

Fonte: Santana e Dantas, (2007)

Seja idealizado como uma espécie de paraíso perdido - uma natureza ainda não corrompida pela civilização -, seja revelado de forma fria e brutal, o sertão é certamente um dos temas privilegiados da fotografia cearense, mas não é a única paisagem a atrair os olhares e a ensejar a produção de narrativas. O mar é sua contraparte, a outra imagem-matriz que atravessa e orienta boa parte da produção fotográfica no Estado. Mais do que um tema, diríamos, o mar aparece aqui como um dispositivo, uma categoria topológica. Pois são inúmeros os ensaios que se debruçam sobre os verdes mares bravios do Ceará, que procuram narrar a saga dos jangadeiros, das velas do Mucuripe que saem para pescar (como na música de Fagner), dos pescadores que se aventuram diariamente nesse lugar incerto e misterioso (Figura 2) ${ }^{1}$.

1 Em obras como Mucuripe, de Chico Albuquerque, e Sereias, de Fernanda Oliveira e Sérgio Carvalho, o mar é visto como um personagem em si mesmo, enquadrado de modo grandioso e serve como um contraponto à imagem árida do sertão. Ele não constitui apenas um meio físico e natural, mas encerra toda uma simbologia em torno das possibilidades 
Figura 2 - Sereias (2016)

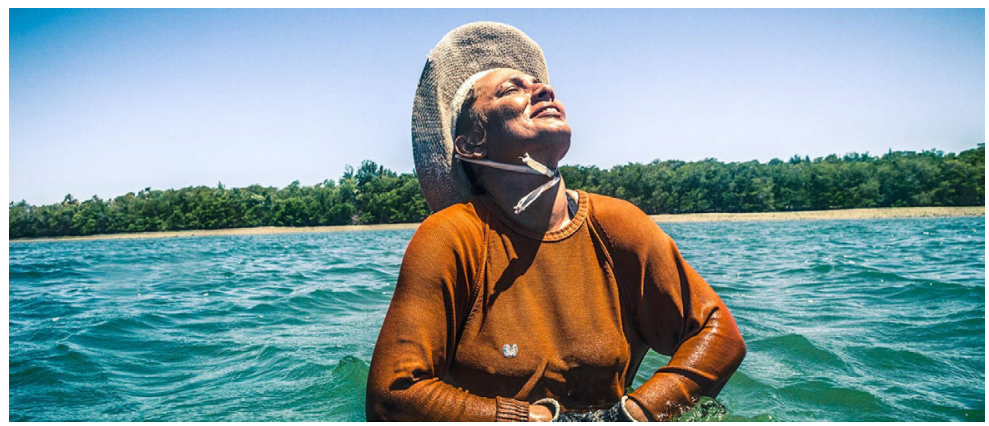

Fonte: Oliveira e Carvalho (2016)

"O sertão vai virar mar e o mar vai virar sertão"! Atribuída a Euclides da Cunha, a frase final de Deus e o Diabo na Terra do Sol, de Glauber Rocha, tem ares de profecia e sintetiza como poucas as grandes linhas mestras da fotografia cearense. De um lado, o sertão, sua paisagem, seus personagens; de outro, o mar, esse "não-lugar", esse desconhecido. Espremidos entre um e outro, a cidade e a cultura urbana parecem não existir, não ter vida no mundo das imagens. É como se o Ceará fosse reduzido a essas duas forças apenas, a esses dois pólos intrinsecamente ligados à natureza. E, se analisarmos a produção fotográfica do Estado desde suas origens até o início deste século, será preciso constatar que, salvo uma ou outra exceção ${ }^{2}$, a fotografia ignorou a cidade e suas agitações: a pulsação das ruas e a energia das massas, os edifícios e as grandes construções, os transeuntes, flanadores e operários, as lojas e armazéns do centro, o mundo do trabalho, a ascensão e

de mudança e de transformação de vida. Desde as narrativas dos desbravadores, sabemos, o mar é essa figura que a um só tempo amedronta e atrai, mas que nunca deixou de ser o lugar de destino daqueles que buscam mudanças. É que ele sempre esteve ligado a uma certa utopia, sendo o caminho obrigatório para a "terra prometida", a passagem para o "paraíso".

2 Cabe mencionar aqui o trabalho de Nelson Bezerra que, nos anos 1970, fotografou o cotidiano e as transformações pelas quais passou a capital do Estado e o ensaio de Drawlio Joca que, no final dos anos 1990, registrou os trabalhadores da rua Governador Sampaio, no centro de Fortaleza. 
decadência das zonas industriais. Raramente o contexto urbano foi alvo de interesse, raramente ascendeu ao campo da representação visual, tendo permanecido invisível à grande maioria dos fotógrafos e artistas visuais.

\section{A fotografia ocupa a cidade, a cidade ocupa a fotografia}

Nos últimos anos, no entanto, é possível notar uma inflexão estética importante na produção local, uma mudança que se deixa a ver não apenas na reconfiguração dos temas, mas também das formas, dos modos de escrita e expressão. Ao que parece, uma nova geração está surgindo, uma geração cuja formação não passa tanto pelas redações jornalísticas (como ocorria no passado), mas por cursos de graduação e pós-graduação voltados ao estudo da imagem em todas suas dimensões. Falamos aqui dos novos cursos de Cinema e Audiovisual, Design e Mídias Digitais, dos Mestrados em Fotografia e Artes da Universidade Federal do Ceará, e dos cursos especializados do Porto Iracema das Artes e da Travessa da Imagem, entre outros. Esse novo cenário formativo e cultural, que se instalou em Fortaleza a partir dos anos 2010, acabou colocando em movimento novas formas de se fazer e pensar a fotografia no Estado.

De fato, ela se transformou, estendeu-se em novas direções, teceu relações renovadas com as artes e com outros campos culturais, redefinindo radicalmente nossa maneira de entender e de lidar com o meio. Aparentemente, um novo regime de visualidade está emergindo, novas formas de ver e mostrar vem sendo colocadas em prática nas obras de fotógrafos contemporâneos. E, dentro desse contexto de reconfiguração estética e política, a cidade surge como um novo centro de interesses, como uma das principais linhas de força dessa nova produção local.

De um lado, parece haver um desejo de se (re)descobrir cidades como Fortaleza, de revelar essa capital múltipla e 
complexa, que durante tanto tempo permaneceu "invisível". Na obra de fotógrafos como Beto Skeff, Marília Oliveira, Regis Amora e Jean dos Anjos, por exemplo, o que está em jogo é a instauração de novos modos de ver a cidade, a constituição de um olhar que pretende desvelar uma Fortaleza ainda não vista, uma cidade "esquecida", seja pelo olhar espetacularizado da grande mídia, seja pelas antigas narrativas visuais que privilegiavam outras questões (Figura 3). De outro, vemos surgir uma série de obras que pretendem problematizar e intervir na cidade, que buscam instaurar através do meio fotográfico novas maneiras de ocupar e redesenhar o espaço urbano.

Figura 3 - Fotografia de Luiz Alves (2015)

Fonte: Reprodução feita na exposição Urbe: Fragmentos Imaginários,

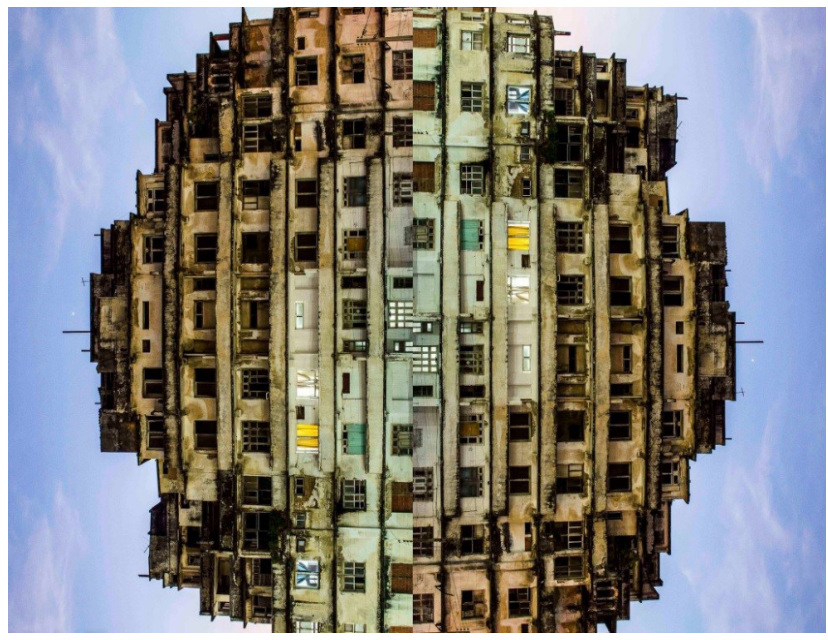

Espaço Dona Chica, 2015.

Não é preciso enfatizar aqui a paixão dos fotógrafos pela cidade. Sabemos que, desde seu nascimento, a imagem fotográfica se viu seduzida por esse símbolo complexo e inesgotável da existência humana, que, em todos os tempos, o meio urbano foi um tema privilegiado da tradição fotodocumentária. Mais do que um tema, a cidade é uma obsessão amplamente compartilhada, 
uma obsessão que levou fotógrafos renomados como o alemão Albert Renger-Patzsch, a eleger, ainda nos tempos áureos das vanguardas, a metrópole, o meio urbano industrial, como o caminho para a autonomia estética e formal da fotografia. Para ele, "a fotografia deveria rechaçar o sentimentalismo e o romantismo e dirigir-se à realidade de uma sociedade profundamente marcada pela urbanidade, desenvolvimento técnico e expansão industrial continuada" (apud OLIVEIRA JUNIOR, 2001).

O que nos surpreende, no contexto específico da produção cearense, é o espaço que a cidade ganhou em tão pouco tempo. De objeto esquecido, negligenciado, ela se tornou o tema central de um sem número de ensaios e exposições ${ }^{3}$. Diante desse cenário, caber-nos-ia perguntar qual a razão e o sentido dessa reviravolta. Se a cidade e a cultura urbana sempre foram um campo fértil de produção de imagens, por que só agora a fotografia cearense parece ter voltado os olhos (de um modo mais coerente e sistemático) a esse universo? Por que, nos últimos anos, o mar e o sertão passaram a dividir cada vez mais espaço com as questões advindas da cultura e do imaginário urbanos? Obviamente, não há uma única resposta a essa questão, mas nossa hipótese é de que o recente interesse pelo meio urbano tem uma natureza de ordem tanto estética quanto política.

Nos últimos 20 anos, as metrópoles brasileiras passaram por transformações que modificaram radicalmente sua paisagem. Apostando numa conduta de verticalização conduzida por grandes empreiteiras, elas construíram verdadeiros paredões ${ }^{4}$, ilhas de concreto que contribuíram decisivamente para a privatização do espaço público, para o sentimento de segregação e isolamento que já imperava nas capitais brasileiras. Ao mesmo tempo, essa

3 Só em 2015 foram três grandes exposições em Fortaleza: A cidade que nos olha, de Silas de Paula, no museu da indústria; A Fortaleza dos seres invisíveis, de Antonello Veneri, na Praça do Ferreira; e a exposição coletiva Urbe: fragmentos imaginários, no centro cultural Dona Chica.

4 Basta ver o projeto das Torres gêmeas no centro histórico do Recife, os novos prédios na orla de Fortaleza, Natal e Salvador. 
construção desenfreada de novos edifícios favoreceu a degradação do patrimônio histórico e cultural das cidades, já que ela se faz, em boa parte das vezes, em cima da destruição de casarios e prédios (muitos deles tombados) que não resistem ao poder da especulação imobiliária. Todo esse processo acaba colocando em movimento um "projeto" de urbanização que desfigura e desumaniza o espaço urbano, gerando uma série de problemas que afetam a todos diariamente.

Pois bem. Embora esse processo de transformação abusiva ocorra em toda parte, nos últimos anos ele tem se intensificado especialmente nas regiões norte e nordeste do país. Recife, por exemplo, num período de apenas dez anos, tornou-se a vigésima primeira cidade mais vertical do mundo, e é seguida de perto por Fortaleza, Salvador e Natal. Movimentos como Ocupe Estelita, em Recife, contra a construção do aquário e do viaduto sobre o Parque do Cocó, em Fortaleza, contra a edificação do La Vue em Salvador - um prédio de 30 andares a ser construído na Ladeira da Barra, sítio histórico e patrimônio cultural da primeira capital do Brasil são alguns dos exemplos de luta, das tentativas de questionamento e problematização desse modelo dominante de (des)urbanização.

Ora, a fotografia participa ativamente desse processo de resistência e ocupação urbana. Boa parte dos ensaios produzidos em Fortaleza nos últimos cinco anos, levanta um debate sobre as transformações radicais pelas quais passa a capital do Estado e se dedica a pensar, no fundo, a forma como o projeto de desenvolvimento urbano vem sendo conduzido no Brasil. Tratase de apontar contradições, incoerências e, sobretudo, de tornar visível as relações de força e os jogos de poder responsáveis por essas mudanças.

Mas, diante de um desenvolvimento urbano descontrolado e assombroso como este, caberia ainda perguntar: o que pode a fotografia? De que modo ela pode lidar com essas transformações, apontando para novas paisagens e experiências possíveis? Como a fotografia pode intervir na cidade, reconfigurando os territórios 
sensíveis, inventando novas de viver e habitar juntos?

Nesse artigo, nos interessa pensar essa relação entre fotografia e cidade, entre o "discurso" fotográfico e a experiência urbana, tendo como ponto de partida uma perspectiva teórica que entrelaça estética e política. Dialogando com os trabalhos de Walter Benjamin, Michel de Certeau e Jacques Rancière, gostaríamos de propor aqui uma conversa, uma interseção teórica e analítica, com o ensaio Gente no Centro (2012), do fotógrafo, professor e pesquisador Silas de Paula. Não é nossa pretensão realizar uma análise precisa e pormenorizada de cada uma das imagens que compõe o ensaio, mas esboçar um exercício de leitura, um olhar preliminar que nos ajudará a introduzir melhor nossas questões, a estruturar as ideias propostas, estabelecendo diálogos neste exercício reflexivo em que nos lançamos.

\section{Cidades mutantes, imagens insurgentes}

Em A invenção do cotidiano, Michel de Certeau (2007) nos mostra que ainda que o planejamento urbano constitua um conjunto de estratégias verticais, ainda que exista uma ordem espacial que organiza um conjunto de possibilidades e proibições, essas forças coexistem o tempo todo com uma série de movimentos contraditórios, de contra-poderes criativos e astuciosos que reinventam modos de fazer, táticas de resistências e sobrevivência que desestabilizam discursos consolidados, ocupando e transformando o espaço urbano. Ainda que pequenos, invisíveis, essas astúcias proliferam nas brechas, nas dobras do sistema, propondo variações, atualizando possibilidades, inventando novas formas de se deslocar, viver e praticar a cidade. De acordo com Certeau, a cidade é, antes de mais nada, um lugar de transformações e apropriações.

Hoje, sejam quais forem os avatares desse conceito, temos de constatar que se, no discurso, a cidade serve de baliza ou marco totalizador e quase mítico para as estratégias sócio-econômicas e políticas, a vida urbana deixa sempre 
mais remontar àquilo que o projeto urbanístico dela excluía. A linguagem do poder "se urbaniza", mas a cidade se vê entregue a movimentos contraditórios que se compensam e se combinam fora do poder panóptico. A cidade se torna o tema dominante dos legendários políticos, mas não é mais um campo de operações programadas e controladas. Sob os discursos que a ideologizam, proliferam as astúcias e as combinações de poderes sem identidade, legível, sem tomadas apreensíveis, sem transparência racional - impossíveis de gerir (CERTEAU, 2007, p.174).

Mas para que essas astúcias e práticas insurgentes possam proliferar é preciso, em primeiro lugar, (re)ver a cidade, (re)descobrila, tornar visível aquela parte/parcela que os discursos dominantes (sejam eles verbais ou visuais) se esforçam em negar, em esquecer, obliterar - especialmente numa cidade como Fortaleza que durante tanto tempo permaneceu invisível, carente de representações visuais. Ora, é para essa parte excluída da cidade que Silas de Paula volta sua câmera: para os trabalhadores do centro, os moradores de rua, os transeuntes, os habitantes invisíveis do cotidiano urbano.

Silas é um cronista urbano, um fotógrafo apaixonado pela "poesia das ruas". E, como dizia o jornalista e teatrólogo João de Rio (2008, p.15), "as ruas tem alma”. "É possível conhecer seu espírito, seu comportamento", mas, para isso, é preciso imergir no cotidiano urbano, se adequar ao ritmo da cidade, agir rapidamente como quem capta as coisas em pleno vôo; é preciso saber ler os detalhes e, sobretudo, saber se perder, guardar em si o prazer e a astúcia da deriva. Pois, como bem notou Walter Benjamin (2000, p.39-40) - o primeiro filósofo a se debruçar seriamente sobre a figura do flâneur, esse amante e príncipe das ruas - "saber orientarse numa cidade não significa muito", difícil mesmo é "perder-se numa cidade, como alguém se perde numa floresta", isso requer instrução, aprendizado.

"Não saberia dizer como as ruas me fazem falta", disse certa vez Charles Dickens. "É como se as ruas me dessem ao 
cérebro algo de que não pode prescindir se quiser trabalhar" (apud BENJAMIN, 1989, p.46). Para muitos escritores e artistas, com efeito, as ruas compõem uma paisagem encantada, fascinante e, nesse mundo em miniatura, entre as bancas de jornal, os muros pixados, os letreiros e o caos do tráfego, eles se sentem em casa, "tanto quanto o burguês entre suas quatro paredes" (BENJAMIN, 1989, p.35). Silas é desses a fazer "botânica no asfalto" - segundo a célebre fórmula de Benjamin - e se filia, assim, a uma rica tradição da qual fazem parte Henri Cartier-Bresson, Robert Doisneau, Garry Winogrand, Lee Friedlander, entre outros. Fotógrafos-andarilhos, flâneurs, eles privilegiam não a arquitetura, a fachada dos prédios, a cidade-monumento que tanto atraiu vanguardistas como Alexander Rodchenko e Laszlo Moholy-Nagy, mas a pulsação das ruas, com toda sua energia, seus encontros e desencontros, suas estranhezas felizes e inesperadas. A rua como um palco onde se desenrolam os dramas e os sonhos cotidianos, lugar de fluxos e lendas, de discursos e contatos culturais.

Figura 4 - Gente no Centro (2011)

Fonte: Klatau Filho (2011, p. 25).

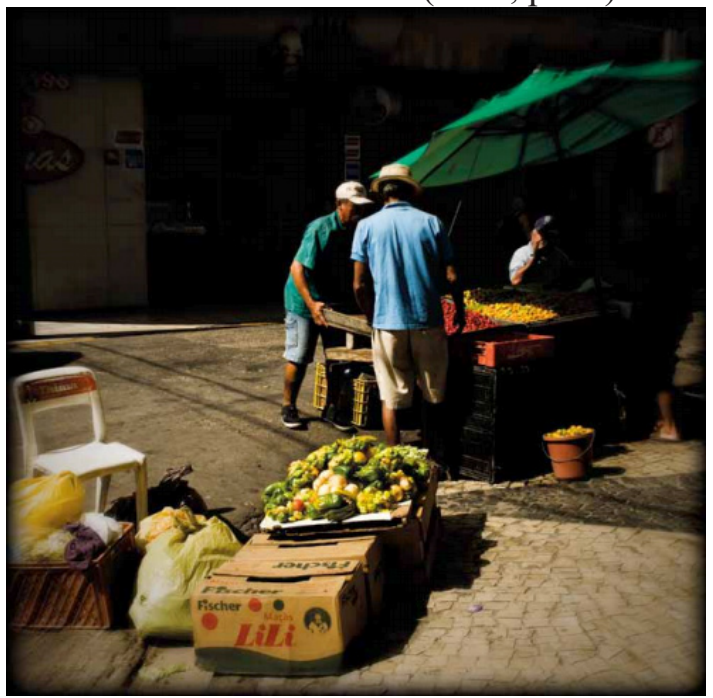

Ao contrário da tradição construtivista, portanto, que via 
a cidade como um instrumento de depuração do olhar, o meio de publicidade do design moderno, esses fotógrafos a vêem como o lugar da aventura e do situacional, das deambulações oníricas no cotidiano urbano (neste caso, menos sítio que situação). Para eles, a rua é uma fonte rica e inesgotável de histórias, um lugar intrinsecamente ambíguo e indeterminado, ligado ao fluir da vida - local de modulação permanente, onde as formas aparecem e logo se esvaem, se deformam, lugar de transformação e de devir constante. Ao mesmo tempo, a rua é o teatro da história, o palco onde podemos decifrar os signos do passado e do futuro, da macro e da micro-história. Nas palavras de Gilles Mora (1998, p. 35), a rua é "um teatro, uma testemunha da intrincada dinâmica da vida [...] o gatilho de muitos tipos de poesia".

Tal como Bresson e Doisneau, Silas costuma registrar seus temas enquanto se movem e se transformam rapidamente diante dele. Trata-se de tentar captar o acidental, a forma instável e fugida, o fluxo da vida em sua dinâmica de formação e deformação permanente. No ensaio Gente no Centro (2011), ele procurou enfocar o problema do trabalho informal no centro da capital cearense. Sua câmera nos mostra os vendedores ambulantes invadindo as ruas do centro, tomando conta das praças e calçadas, dos espaços inicialmente reservados aos transeuntes. O resultado é uma espécie de "mercado persa", uma situação complexa, a um só tempo, colorida e desordenada, vibrante e caótica. Fruto do desemprego e do descontrole social, essa é não uma cena exclusiva da capital cearense, mas algo que se repete em boa parte das metrópoles brasileiras. A falta de planejamento social e urbano acaba produzindo uma vida caótica nos centros, uma situação que altera a paisagem urbana, dificultando a mobilidade e degradando os bairros históricos.

Mas, se para Bresson e Doisneau o que interessava eram os momentos líricos, os lampejos de beleza, aquelas justaposições fortuitas em que tudo parece ganhar coerência num tom mágico, para Silas é exatamente a energia das massas que atrai, a alta 
voltagem das ruas, o caos urbano. Suas lentes vão sempre em busca da selva urbana, mas através de um engajamento contemplativo e algo distante (Figura 5).

Figura 5 - Gente no Centro (2011)

Fonte: Klatau Filho (2011, p. 26)

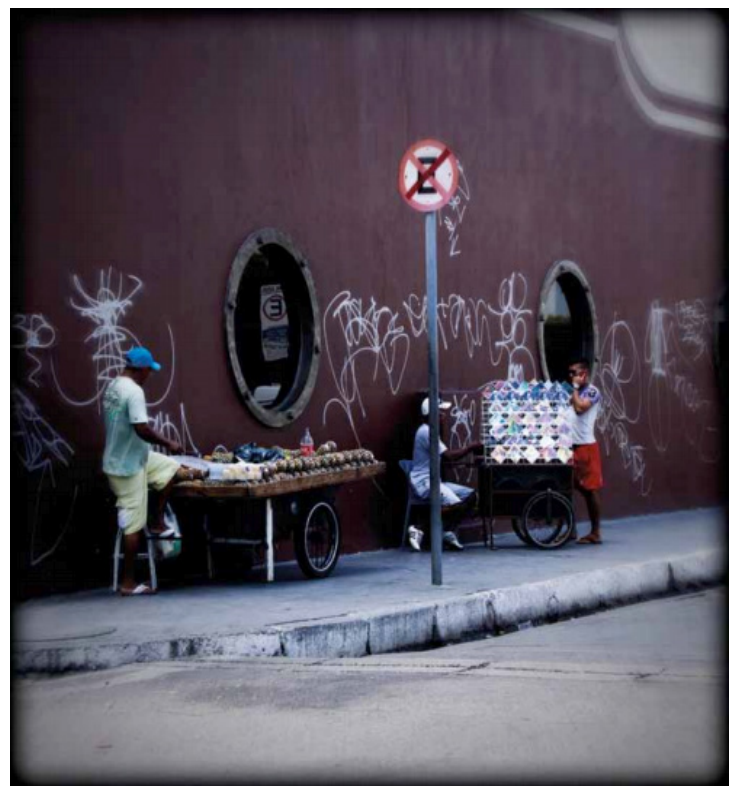

Ao analisar as imagens de Gente no Centro (2011), o crítico e fotógrafo paraense, Mariano Klautau Filho (2011, p.15), destaca o "olhar mais demorado sobre a cena", um modo mais concentrado e reflexivo "em que significados diversos surgem liberados de uma visão ligeira sobre os fatos". Ao contrário de uma sensibilidade documental clássica (LUGON, 2011), portanto, que opera por meio da denúncia, que joga freqüentemente com o sentimentalismo e a indignação moralista - um posicionamento que Jacques Rancière enquadraria dentro do paradigma da conscientização ou de causa e efeito - Silas prefere pôr em movimento um olhar mais sutil e delicado, um olhar que se demora sobre as coisas, atento aos 
pequenos detalhes, a gestos mínimos, mas que tenta, ao mesmo tempo, guardar uma certa distância, pôr de lado todo julgamento, toda assertiva moral.

Sustentar a distância é investir num olhar que contempla, mais do que julga ou interroga, é acreditar na força descritiva e revelatória das imagens, evitando a sobreposição de significações e de enquadres pré-estabelecidos. Trata-se de um olhar que investe no paradigma do visual, que se quer, num certo sentido, autônomo em relação ao texto (ao verbal), valorizando o que há de indizível e misterioso nas imagens. Isso não quer dizer, evidentemente, que Silas não module e, em certa medida, (re)crie essa "realidade", empreendendo ao caos do centro uma visão marcadamente pessoal. De fato, ele prima pelo rigor formal e tenta impor a uma cena intrinsecamente confusa e desordenada uma coerência visual. Não há como negar o apreço pela boa composição, o gosto pela ordem, a tentativa de encontrar a harmonia até mesmo no coração do caos.

É como se o fotógrafo quisesse encerrar toda a cacofonia palpitante dos ambulantes no centro num todo harmônico e coerente. Klatau Filho chega a falar em um "contra-discurso à realidade", uma contra-narrativa que muda a forma como enxergamos o centro. De acordo com o crítico paraense, Gente no Centro (2011) "ultrapassa seu objetivo documental e cria um ambiente onírico e solitário" (KLATAU FILHO, 2011, p.15), onde se destaca um colorido triste, uma certa beleza silenciosa, melancólica, que deixa entrever o olhar cúmplice do fotógrafo para com aqueles que vivem e trabalham no centro. Numa palavra, Silas não apenas chama atenção para uma parte/parcela de Fortaleza que estava esquecida, relegada, mas, ao fazê-lo, cria novas visualidades, muda nossa forma de ver e de pensar o espaço urbano, (re)significando a cidade (Figura 6). 
Figura 6- Gente no Centro (2011)

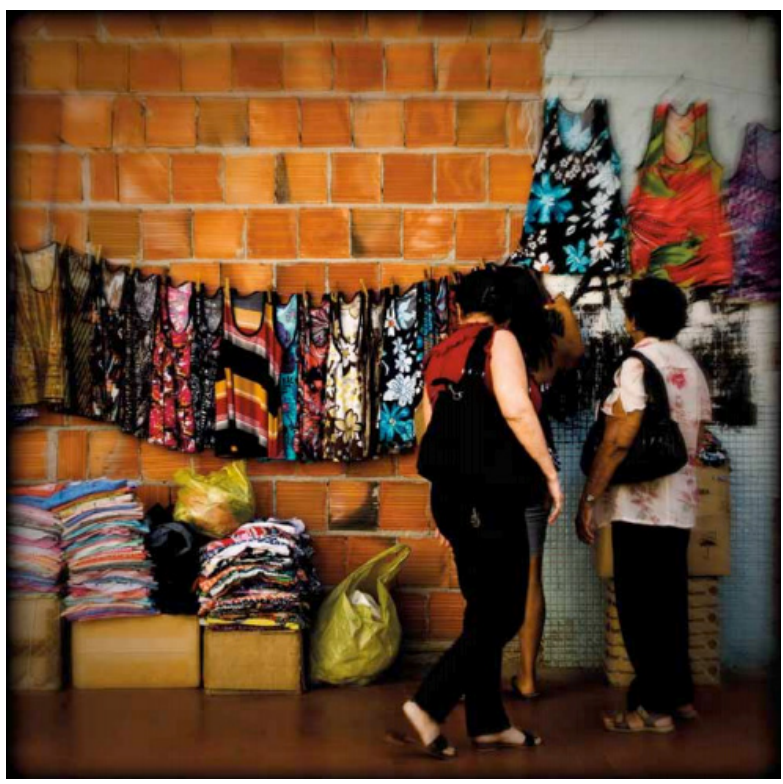

Fonte: Klatau Filho (2011, p. 27).

\section{Considerações Finais}

Nesse gesto, Gente no centro (2011) faz com que o morador fortalezense observe mais o seu entorno, conheça sua história e comece, quem sabe, a se apropriar mais do espaço urbano, a se reconectar com sua cidade. A fotografia funciona aqui, portanto, menos como um "relógio de ver" - segundo a feliz expressão de Roland Barthes (2015) - um instrumento cuja tarefa principal seria restituir as formas de um mundo preexistente e mais como um dispositivo de encontro e (re)descoberta da cidade, um aparelho relacional capaz de promover uma espécie de flânerie contemporânea, de instigar novas maneiras de ver e ocupar o espaço urbano.

Nas crônicas visuais de Silas, com efeito, a fotografia aparece 
como uma potente ferramenta de aproximação e desvendamento da cidade, um instrumento disparador de encontros, capaz de nos abrir ao outro (aos ambulantes, transeuntes, flanadores, aqueles que vivem e trabalham no centro), construindo o que Rancière (1996, p.68) denomina "cenas dissensuais", isto é, imagens insurgentes produzidas em contexto de disputa política e nas quais se inscreve um desejo de transformação social.

Ora, esse modo de ver as coisas nos permite distinguir alguns aspectos fundamentais subjacentes não apenas ao ensaio de Silas, mas a esta nova produção que surge hoje no Ceará 5 . De um lado, parece haver uma confiança inabalável na dimensão política das imagens, na sua capacidade de desestabilizar discursos e imaginários consolidados, manifestando modos de existência dissensual do sensível. Confiança, diríamos, na "capacidade de resistência da arte no interior do campo social" (BOURRIAUD, 1998, p.31). E, sustentando essa postura política, uma percepção mais complexa e sofisticada da fotografia que, nesses trabalhos, é vista e tomada não mais como imagem-documento, mero registro do real, mas em seu aspecto "construtor", como um aparato que, em certo sentido, "produz" a realidade, que organiza e "constrói" poeticamente o visível.

Em sua Filosofia da caixa preta, Flusser já criticava o paradigma da verossimilhança, essa concepção algo persistente da fotografia como "espelho do real", como uma janela para o mundo. Para o filósofo tcheco-brasileiro, o que as imagens técnicas nos oferecem não é o mundo, mas conceitos relativos a ele. Isso porque, a fotografia é, antes de tudo, "uma construção" e sua aparente objetividade é apenas ilusória, "pois na realidade [elas] são tão simbólicas quanto o são todas as imagens" (FLUSSER, 2011, p. 31). Na mesma linha de raciocínio, André Rouillé (2009) vai defender que a fotografia constrói mundos, que entre o "real" e as imagens se interpõe uma série de conceitos, valores, desejos - "operantes 5 Além de Silas, poderíamos citar ainda os trabalhos de Beto Skeff, do Descoletivo (formado pelos fotógrafos Marília de Oliveira e Regis Amora), da Iana Soares, Felipe Acácio, Deivyson Teixeira, Jean dos Anjos, entre outros. 
que se constituem em ordem visual, em prescrições icônicas e em esquemas estéticos" (ROUILLÉ, 2009, p. 136). Por esse motivo, segundo o teórico francês, mesmo o documento considerado mais puro e objetivo é inseparável de uma "expressão", de um conjunto de convicções estéticas, sociais e políticas, que denota, no fundo, uma certa visão de mundo.

O processo fotográfico é concebido como um meio de liberar - por eliminação, corte e simplificação - a verdade, que está oculta, da realidade visível. [...] Mas isso traz a desvantagem de considerar a imagem fotográfica como um simples recorte de um real existente, enquanto fotografar consiste em transformar o real em um real fotográfico. Não recortar-registrar, mas transformar, converter. A fotografia reproduz menos do que produz; ou melhor, ela não reproduz sem produzir, sem inventar, sem criar, artisticamente ou não, uma parte do real nunca o real em si (ROUILLÉ, 2009, p. 132).

Numa palavra, podemos dizer que a fotografia se apresenta, a um só tempo, como impressão (vestígio, rastro do real) e criação, um lugar de memórias (arquivo vivo do tempo) e um objeto de sonho, objeto da ciência (Warburg) e de não saber (Bataille). Voltando aos ensaios urbanos produzidos recentemente no Ceará, diríamos que neles a fotografia não apenas documenta as transformações ocorridas, mas, ao fazê-lo, forja e enaltece uma determinada imagem de cidade. Muito aquém (ou além) de um registro, de fato, ensaios como Gente no Centro (2011) se constituem como veículos propagadores de um imaginário que, ao mesmo tempo, questiona e recria, problematiza e transforma o meio urbano. Eles não apenas representam, mas intervêm na cidade, tomando parte nas disputas e dinâmicas políticas pelo uso e pela configuração do espaço urbano.

Se concordamos com autores como Benjamin, Certeau e Rancière, sabemos que a política é interior à linguagem, que é indissociável de seus gestos, movimentos, materialidades, modulações. Não se trata de algo exterior, algo que poderíamos 
facilmente capturar e transmitir. De acordo com Rancière (2005), são as próprias imagens, enquanto formas que pensam, enquanto acontecimentos sensíveis, que agem no mundo, que abrem brechas nas experiências, instaurando novos possíveis. É o próprio gesto de fotografar que pode operar torções nas distribuições dadas do sensível, inventando novos espaços para habitar, outros tempos para sentir, novas formas de estar juntos na cidade. Afinal, tanto a arte quanto a política se ocupam, no fundo, dos mesmo problemas: "o desafio é sempre como se colocar no mundo, como se relacionar com as tendências em jogo e adotar posturas críticas, para que os novos modos de ver não se tornem o instituinte, o elemento ordenador e policial” (DE PAULA; OLIVEIRA; LOPES, 2013).

\section{Referências}

ALENCAR, José. O Sertanejo. São Paulo: Rideel, 1997.

BARTHES, Roland. A câmara clara: nota sobre a fotografia. Rio de Janeiro: Nova Fronteira, 2015.

BENJAMIN, Walter. Rua de mão única. São Paulo: Brasiliense, 2000. (Obras escolhidas II).

. Charles Baudelaire, um lírico do auge do capitalismo. São Paulo: Brasiliense, 1989. (Obras escolhidas III).

BOURRIAUD, Nicolas. Esthétique relationnelle. Dijon: Les Presses du reel, 1998.

CALVINO, Italo. As cidades invisíveis. 2. ed. São Paulo: Cia. das Letras, 2004.

CERTEAU, Michel. A invenção do cotidiano: artes de fazer. 
Petrópolis: Vozes, 2007.

DE PAULA, Silas; OLIVEIRA, Araújo; LOPES, Leila. Imagens que pensam, gestos que libertam: apontamentos sobre estética e política na fotografia. In: BRASIL, André; MORETTIN, Eduardo; LISSOVSKY, Maurício (Org.). Visualidades Hoje - Livro Compos. Salvador: Edufba, 2013. p. 263-282.

FLUSSER, Vilém. Filosofia da Caixa Preta: ensaios para uma futura filosofia da fotografia. São Paulo: Hucitec, 2011.

KLATAU FILHO, Mariano. Cidades Possíveis. In: KLATAU FILHO, Mariano etal. Catálogo do Prêmio Diário Contemporâneo de Fotografia: Crônicas Urbanas. Belém: Diário do Pará, 2011.

LUGON, Olivier. Le style documentaire. D'August Sander à Walker Evans, 1920-1945. Paris: Éditions Macula, 2011.

MORA, Gilles. Photo speak: a guide to the ideas, movements, and techniques of photography. New York: Abbeville Press, 1998.

OLIVEIRA JUNIOR, Antônio R. Reconstruindo a imagem: a nova visualidade, a fotografia e a cidade. 2001. Disponível em: $<$ http://www.compos.org.br/data/ biblioteca_1225.pdf $>$. Acesso em: abr. 2015.

OLIVEIRA, Fernanda; CARVALHO, Sérgio. Sereias. Fortaleza: Tempo d'Imagem, 2016.

RANCIÈRE, Jacques. A partilha do sensível: Estética e política. 2.ed. São Paulo: Ed. 34, 2005.

. O desentendimento. São Paulo: Ed.34, 1996. 
RIO, João do. A alma encantadora das ruas. São Paulo: Companhia de Bolsa, 2008.

ROUILLE, Andre. A fotografia entre documento e arte contemporânea. São Paulo: Senac, 2009.

SANTANA, Tiago; DANTAS, Audálio. O chão de Graciliano. Fortaleza: Tempo d'Imagem, 2007. 